\title{
Overexpression of the opioid growth factor receptor potentiates growth inhibition in human pancreatic cancer cells
}

\author{
IAN S. ZAGON ${ }^{1}$, MICHAEL F. VERDERAME ${ }^{2}$, JODY HANKINS ${ }^{1}$ and PATRICIA J. McLAUGHLIN ${ }^{1}$ \\ Departments of ${ }^{1}$ Neural and Behavioral Sciences, and ${ }^{2}$ Medicine, \\ The Pennsylvania State University College of Medicine, Hershey, PA 17033, USA
}

Received November 15, 2006; Accepted December 28, 2006

\begin{abstract}
The opioid growth factor (OGF), [Met $\left.{ }^{5}\right]$-enkephalin, and OGF receptor (OGFr) form an inhibitory axis regulating the growth of human pancreatic cancer. This study examined whether overexpression of OGFr decreases the growth of pancreatic cells in vitro. MIA PaCa-2 cells were transfected with OGFr cDNA, and six clonal lines were examined for protein expression and function. OGFr binding assays revealed a 2.3- to 5.6-fold increase in binding capacity from wild-type (WT) and empty vector (EV) controls; binding affinity was comparable in all groups. OGFr protein expression, as measured by immunohistochemistry and Western blotting, was enhanced in clonal cell lines compared to controls. Doubling times of OGFr clonal lines were $47-91 \%$ longer than in the WT/EV groups for all but one clonal line. DNA synthesis of cells overexpressing OGFr was diminished from the WT/EV groups by $28-52 \%$. Addition of exogenous OGF further reduced (14-31\%) the cell growth of clonal lines, and the effects of exogenous OGF were receptor-mediated. Exposure of cells overexpressing OGFr to naltrexone increased the cell number by up to 9.4 -fold. OGF was identified as the only opioid peptide to depress cell replication in the transfected cell lines. Neutralization of endogenous OGF with antibodies to this peptide elevated the cell number in clonal cell lines. These data identify OGFr at the molecular level as integral to regulating the cell replication of human pancreatic cancer, and support treatment modalities that amplify OGFr in order to decrease the growth of these neoplasias.
\end{abstract}

\section{Introduction}

Pancreatic cancer is estimated to be 10th in the number of new cases of cancer in the United States and, with a $98 \%$

Correspondence to: Dr Ian S. Zagon, Department of Neural and Behavioral Sciences, H109, The Milton S. Hershey Medical Center, 500 University Drive, Room C3729, Hershey, PA 17033, USA

E-mail: isz1@psu.edu

Key words: opioid growth factor receptor, pancreatic cancer, opioids, transfection, DNA synthesis mortality rate, is the 4 th leading cause of cancer-related deaths (1). Globally, pancreatic cancer occurs in more than 168,000 individuals each year, and is the 9th leading cause of mortality from cancer (2). The 5-year survival rate is $5 \%$ for patients with cancer of the pancreas (1), and has changed only $2 \%$ in the last several decades, carrying one of the most dismal prognoses (3). The problem of treating pancreatic cancer is compounded by a lack of early detection tools, resulting in $80 \%$ or more of patients having unresectable cancer at the time of initial diagnosis $(4,5)$.

The opioid growth factor (OGF), chemically termed [Met ${ }^{5}$-enkephalin, is an endogenous opioid peptide that is an important regulator of the growth of human pancreatic cancer (6-18, Cheng F, et al, AACR 97th Ann Meet: abs. 2077, 2006). OGF is a constitutively expressed native opioid that is autocrine produced and secreted, and interacts with the OGF receptor (OGFr) to inhibit the growth of pancreatic cancer cells in vitro and in tumor xenografts $(7,11,12)$. The action of OGF is tonic, stereospecific, reversible, non-cytotoxic and non-apoptotis inducing, not associated with differentiative processes, serum- and anchorage-independent, and occurs at physiologically relevant concentrations in a wide variety of pancreatic cancers including poorly- and well-differentiated human cell lines $(7,11,12,16-18)$. The only opioid peptide, natural or synthetic, that influences the growth of pancreatic cancer is OGF $(7,11)$. The action of this opioid in these neoplasias is targeted to DNA synthesis (15) and is directed toward the $\mathrm{G}_{0} / \mathrm{G}_{1}$ interface of the cell cycle (15, Cheng F, et al, AACR 97th Ann Meet: abs. 2077, 2006), specifically the cyclin-dependent inhibitory kinase pathways (Cheng F, et al, AACR 97th Ann Meet: abs. 2077, 2006). Exogenous administration of OGF has a profound antitumor action on xenografts of pancreatic cancer that includes delaying tumor appearance and reducing tumor size (11-13). The combination of biotherapy with OGF and chemotherapy with gemcitabine has proven to enhance antitumor effectiveness beyond either agent alone (11).

The gene for human OGFr is at least $9 \mathrm{~kb}$ in length, consists of seven exons and six introns, and encodes a 677 amino acid protein that includes 7 imperfect repeats of 20 amino acids each and a bipartite nuclear localization signal $(6,14)$. OGFr has an apparent mass of $62 \mathrm{kDa}$. The chromosomal location of the human OGFr is 20q13.3 (14). Although OGFr has characteristics of a classical opioid receptor (recognizes opioids, naloxone reversibility, stereospecificity), there is no 
homology of OGFr with classical opioid receptors in terms of nucleotides or amino acids $(6,14)$. Antisense experiments with OGFr and continuous blockade of opioid receptors by the potent opioid antagonist naltrexone (NTX) reveal that the OGF-OGFr axis is a tonically active inhibitory system targeted to cell replication and homeostasis, and is ligand-dependent for function $(6,14)$. Immunoelectron microscopy and confocal microscopy studies have shown that OGFr is localized to the outer nuclear envelope, nucleus and perinuclear cytoplasm $(19,20)$. Gene expression $(13,14)$ and protein expression $(7,12,13)$ of OGFr, as well as binding activity $(8,12,13)$ have been identified and characterized in pancreatic cancer cell lines revealing the autocrine nature of this growth regulatory axis.

In this study, we have asked whether the amplification of OGFr signaling in human pancreatic cancer may contribute to phenotypic changes, such as the loss of cell replication, which could be associated with malignant progression. To this end, we have used a tissue culture model of the MIA $\mathrm{PaCa}-2$ cell line, derived from an undifferentiated epithelial carcinoma occurring in the body and tail of the pancreas in a 65-year old man (21), and examined the effect of overexpressing OGFr on cell proliferation. The results show for the first time that overexpression of OGFr at the molecular level decreases cell replication and DNA synthesis of pancreatic cancer cells in tissue culture, indicating that OGFr is integral to the inhibitory action of OGF. The data also establish the fundamental principle that OGF and OGFr form an autocrine loop to regulate the growth of these neoplasias. Upregulation of OGFr may provide a novel target to inhibit pancreatic cancer suggesting that molecular and pharmacological strategies could be utilized for the treatment of this deadly neoplasia.

\section{Materials and methods}

Human tumor cell line. MIA PaCa-2 cells (21) were grown in monolayers at $37^{\circ} \mathrm{C}$ in a humidified atmosphere with $5 \%$ $\mathrm{CO}_{2} / 95 \%$ air in Dulbecco's modified Eagle's medium (DMEM) containing $10 \%$ fetal calf heat inactivated serum, $1.2 \%$ sodium bicarbonate, and antibiotics (5,000 Units/ml penicillin, $5 \mathrm{mg} / \mathrm{ml}$ streptomycin, $10 \mathrm{mg} / \mathrm{ml}$ neomycin).

Transfection and clonal selection. MIA PaCa-2 cells were transfected with pcDNA3.1 ${ }^{+}$vector (empty vector, EV) or with the plasmid pcDNA3.1 + huOGFr in the presence of Lipofectamine 2000. Transfected cells were selected by growth in media containing G418 at $1 \mathrm{mg} / \mathrm{ml} ; 12$ clones were expanded and analyzed for binding capacity and growth. Based on the results of these experiments, six clones were maintained in G418 and characterized. For all experiments, wild-type (parental) cells (WT) and EV cell lines served as controls.

OGFr binding assays. Binding assays for OGFr were performed with procedures described earlier (8). In brief, log-phase cells were harvested, and the nuclear fraction isolated through sucrose gradient centrifugation. Binding saturation isotherms were determined by specific binding of custom-synthesized $\left[{ }^{3} \mathrm{H}\right]$-[Met $\left.{ }^{5}\right]$-enkephalin (Perkin Elmer-
New England Nuclear; $41 \mathrm{Ci} / \mathrm{mmol})$. Assays were performed 3 to 8 times on each cell line.

Immunohistochemistry. To examine the presence of OGFr, log-phase cells from clonal lines, as well as WT and EV, were grown on 22-mm round coverglasses for $72 \mathrm{~h}$. Immunohistochemistry was performed according to methods described previously (7). Cells were fixed and permeabilized in $95 \%$ ethanol, followed by immersion in acetone $\left(-20^{\circ} \mathrm{C}\right)$, and stored at $-20^{\circ} \mathrm{C}$ for no more than 7 days before processing. Cells were incubated with ammonium sulfate purified antiOGFr-IgG (1:250) diluted in Sorenson's phosphate buffer with $1 \%$ normal goat serum in $0.1 \%$ Triton $\mathrm{X}-100$ for $18 \mathrm{~h}$ at $4{ }^{\circ} \mathrm{C}$. Coverglasses were washed and incubated with goat anti-rabbit IgG (1:100) conjugated to rhodamine and viewed with fluorescence microscopy. Antibodies to OGFr (I0029) were generated in the laboratory to a full-length rat OGFr fusion protein (22). This antibody stained the $62-\mathrm{kDa}$ protein of OGFr in a nuclear preparation, as well as proteolysis products of 32-, 30-, 17-, and 16-kDa of OGFr (unpublished observations), and recognized $50 \mathrm{ng}$ of recombinant protein at a 1:100 dilution.

Protein isolation and Western blotting. Cell samples were isolated and nuclear preparations separated on $12 \%$ sodium dodecyl sulphate-polyacrylamide gel electrophoresis, and electrotransferred to nitrocellulose (22). Western blotting was performed with primary antibodies to recombinant rat OGFrGST fusion protein (IO407) (1:500), or with commercially available $\beta$-actin $(1: 10,000)$ (BD Biosciences, Palo Alto, CA). Antibody IO407 detects human (and rat) OGFr at $50 \mathrm{ng}$ at a $1: 100$ dilution, and recognizes the $62-\mathrm{kDa}$, as well as the $32-$, $30-, 17-$, and 16-kDa fragments, of OGFr. This antibody was purified over a glutathione-S-transferase Sepharose 4B column. Western blots were quantitated by densitometric measure of the $62-\mathrm{kDa}$ band of OGFr. The optical density of B-actin was used to standardize the protein load.

Cell proliferation. Transfected cell lines were seeded into 6- or 24-well plates, and cell number (trypan blue exclusion staining) was determined at 24-h intervals over a 3- to 4-day period. Growth curves were generated and doubling times were calculated by nonlinear curve fitting analyses (GraphPad Prism 4.0, San Diego, CA).

DNA labeling indexes. To measure DNA synthesis, cells were plated onto 22-mm round coverglasses and grown in serum-containing media for $48 \mathrm{~h}$ prior to addition of $30 \mu \mathrm{M}$ bromodeoxyuridine (BrdU) for $3 \mathrm{~h}$. Cells were stained with anti-BrdU biotin conjugated primary antibody $(1: 20)$ (Molecular Probes/Invitrogen, Carlsbad, CA), followed by staining with goat anti-mouse HRP secondary antibody (1:1000) (Chemicon, Temecula, CA); BrdU-positive cells were counted from 10 random fields and the percent labeling index calculated. At least 1000 cells/cell line were counted.

Growth in the presence of OGF. To determine whether an overexpression of OGFr changed the response of cells to the inhibitory pentapeptide OGF, transfected cell lines, along with WT and EV cells were grown in the presence of $5 \times 10^{-6} \mathrm{M}$ 
OGF for $72 \mathrm{~h}$. OGF or sterile water was added from $24 \mathrm{~h}$ after seeding $(=0 \mathrm{~h})$; media and compounds were replaced daily. This OGF concentration was selected based on previous evidence demonstrating growth inhibition of pancreatic cancer cells (7).

Opioid receptor mediated growth. To determine whether the transfected cell lines were expressing OGF receptors that responded to pharmacological characteristics defined previously (7), such as blockade by opioid antagonists, transfected cells lines, along with WT and EV cell lines were grown in the presence of $5 \times 10^{-5} \mathrm{M}$ naloxone (Sigma-Aldrich, St. Louis, MO), a short-acting opioid antagonist, $5 \times 10^{-6} \mathrm{M}$ OGF, both $5 \times 10^{-6} \mathrm{M}$ OGF and $5 \times 10^{-5} \mathrm{M}$ naloxone, or sterile water. Treatments began $24 \mathrm{~h}$ after seeding; media and compounds were replaced daily. Cells were counted $48 \mathrm{~h}$ after initiation of drug exposure.

Response to naltrexone. In order to establish the response of cells with amplified OGFr to continuous opioid receptor blockade, cultures of clonal cells including EV, OGFr-1, and OGFr-4 were seeded for $24 \mathrm{~h}$ and treated with NTX at dosages of $10^{-5}$ and $5 \times 10^{-5} \mathrm{M}$ for $48 \mathrm{~h}$; media and drug were changed daily. Some cultures of each cell line received an equivalent volume of sterile water.

Specificity of OGF to cells overexpressing OGFr. To examine the specificity of OGF in cells with amplified OGFr, transfected clonal lines along with parent cells, were seeded at 1000 cells/well into 96-well plates and allowed $24 \mathrm{~h}$ growth prior to addition of a variety of synthetic and natural opioids $\left(10^{-6} \mathrm{M}\right)$; drugs and media were replaced daily. The following compounds were obtained from the indicated sources: dynorphin A1-13, $\beta$-endorphin (porcine), endomorphin-1, endomorphin-2, [D-Pen ${ }^{2,5}$ ]-enkephalin (DPDPE), and [D-Ala ${ }^{2}$, $\mathrm{MePhe}^{4}$, Glycol${ }^{5}$-enkephalin (DAMGO) were from Sigma (St. Louis, MO); morphine sulfate was from National Institutes on Drug Abuse (Rockville, MD); and U69,593 was from Upjohn Pharmaceuticals (Kalamazoo, MI). Cell number was recorded at $72 \mathrm{~h}$ using the MTS proliferation bioassay (Cell Titer 96 One Solution, Promega, Madison, WI), and absorbency was measured after $4 \mathrm{~h}$ on a BioRad (Model 3550) plate reader at $490 \mathrm{~nm}$ with a 750-nm background absorbance screening.

Effect of OGF antibody on cell proliferation. In order to determine if OGF played a role in basal regulation of growth in cells overexpressing OGFr, clonal cell lines and WT, were subjected to 1:200 dilutions of anti-OGF IgG (CO172) (21) and counted $72 \mathrm{~h}$ later. Media and antibody were replaced daily. Previous evidence (7) demonstrated no differences in cell number between non-immune IgG-treated and control cultures.

Statistical analysis. Cell numbers and/or absorbencies, as well as labeling indexes, were analyzed using analysis of variance (ANOVA) with subsequent comparisons made using Newman-Keuls tests. Data from binding assays were subjected to analysis by GraphPad Prism, and binding affinities and capacities were generated with this computer software.

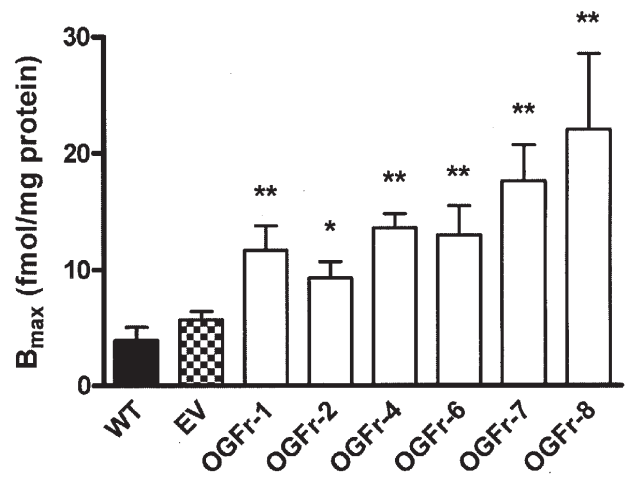

Figure 1. Overexpression of OGFr increased binding capacity (Bmax) values for radiolabeled OGF. Parental cells (WT), and cells transfected with an empty (EV) or pcDNA3.1-OGFr in 6 clonal cell lines were sampled at log phase. Values represent means \pm SE for 3-8 saturation binding isotherms. Significantly different from both WT and EV groups at ${ }^{*} \mathrm{p}<0.05$ and ${ }^{* *} \mathrm{p}<0.01$.

\section{Results}

Establishment and characterization of the OGFr clones. To study the effects of amplification of the OGF receptor on growth, MIA PaCa-2-derived clones that overexpressed OGFr were established. To generate these clones, MIA PaCa-2 cells were stably transfected with an OGFr expression vector, and 12 neomycin-resistant clones were characterized for OGF receptor binding and growth at $72 \mathrm{~h}$ after seeding (data not shown). Six clones (OGFr-1, -2, -4, -6, -7, and -8) with different levels of receptor expression as compared to the parental MIA PaCa-2 cell lines were expanded and further characterized (Figs. 1-7). For all studies, comparisons were made to WT and/or EV cell lines.

Overexpression of OGFr upregulates receptor binding capacity. To characterize further the MIA PaCa-2/OGFr clones, we determined the binding affinity $(\mathrm{Kd})$ and binding capacity (Bmax) for each transfected cell line. Binding assays of radiolabeled $\left[\mathrm{Met}^{5}\right]$-enkephalin for OGFr revealed specific and saturable binding in the nuclear enriched fraction of all cell lines. Binding affinities did not differ between WT, EV and clonal cell lines, with $\mathrm{Kd}$ values of $2.4 \pm 0.9 \mathrm{nM}$ and $3.4 \pm 1.0 \mathrm{nM}$ for the WT and EV groups, respectively, and a range of $3.2 \pm 1.2$ to $8.6 \pm 2.1 \mathrm{nM}$ for the mean $\mathrm{Kd}$ levels of clonal cells.

Binding capacity values for clonal cells, however, were

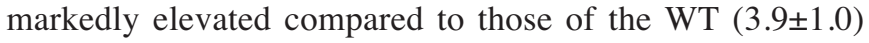
and EV (5.7 \pm 0.7$)$ groups, with increases ranging from 2.3- to 5.6-fold recorded in cells with amplified OGFr (Fig. 1). No differences in Bmax values between the WT and EV groups were noted.

OGFr protein is present and overexpressed in transfected cell lines. In order to confirm that OGFr protein is present and overexpressed at the structural level, immunohistochemical preparations of two selected clonal lines, OGFr-1 and OGFr-7, grown on coverslips for $72 \mathrm{~h}$ were performed using a polyclonal antibody to recombinant OGFr. A marked increase in immunofluorescence of these two clonal cell lines was observed relative to WT (Fig. 2A) and EV cells (data not 


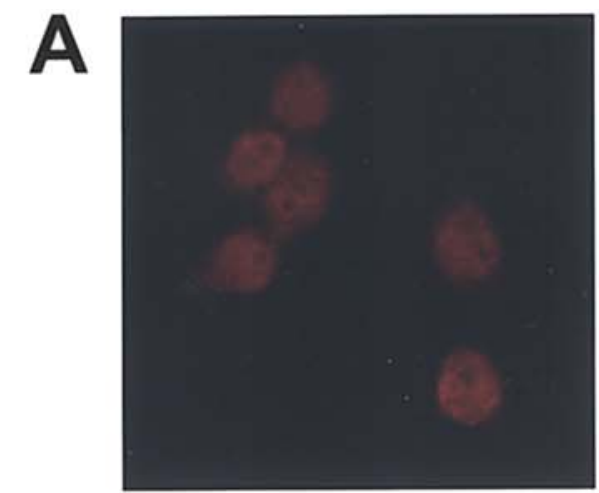

WT

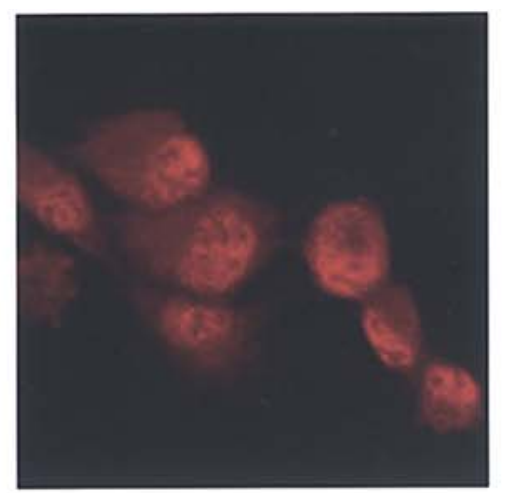

OGFr-1

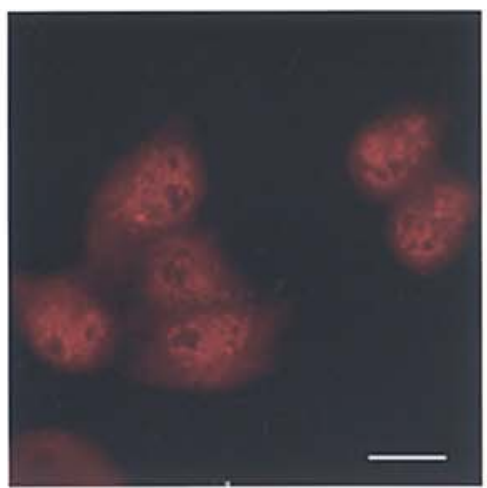

OGFr-7
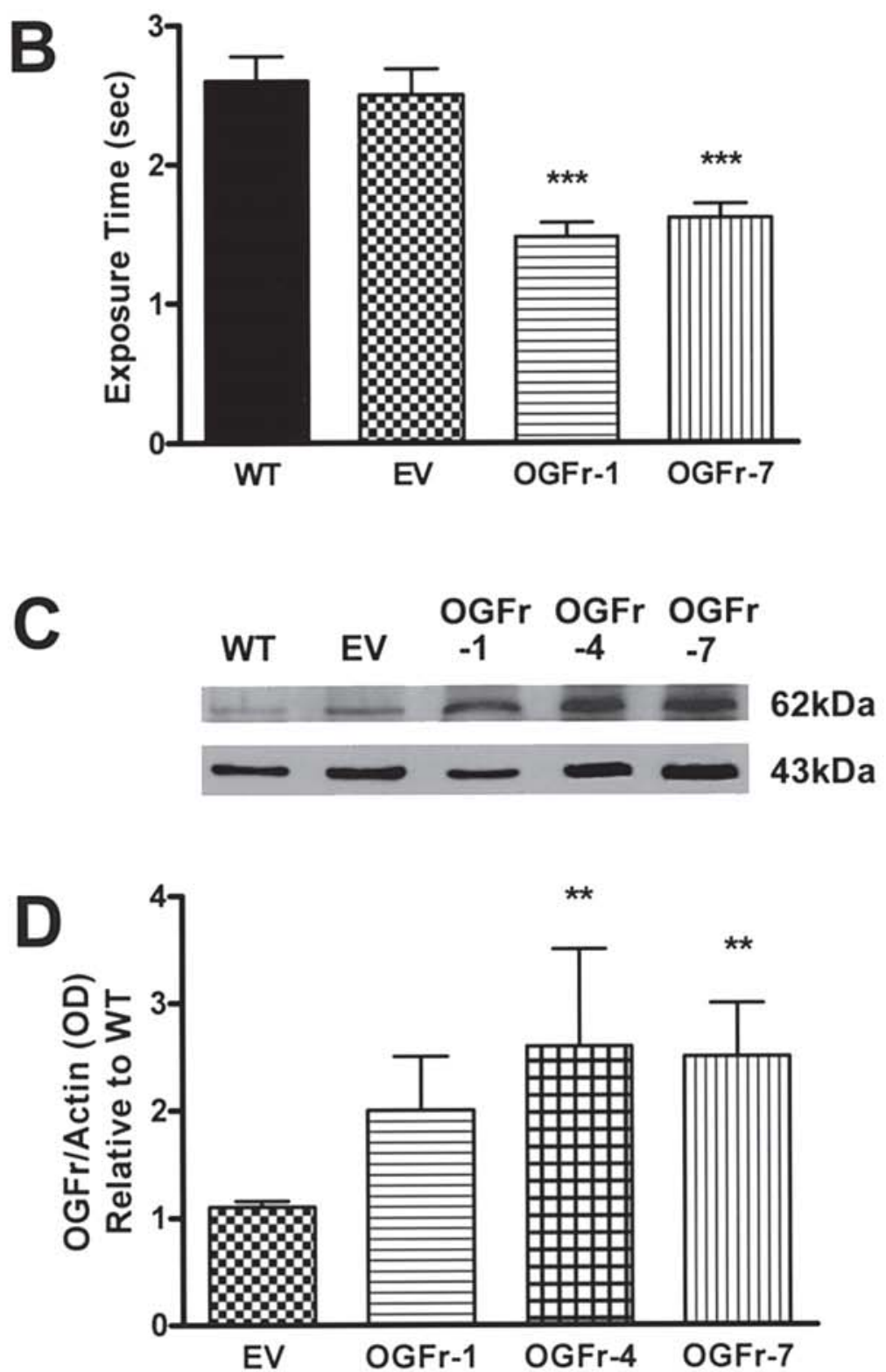

Figure 2. Transfection of OGFr increased translational activity of the receptor. A, immunohistochemical preparations of parent MIA PaCa-2 (WT), as well as cells overexpressing the receptor (OGFr-1 and OGFr-7), stained with an antibody to OGFr. Note the increased immunoreactivity in the specimens overexpressing OGFr. Bar $=10 \mu \mathrm{m}$. B, quantitation of OGFr expression in immunohistochemical preparations using exposure time. Values represent mean \pm SE for at least 10 photodensitometric readings/group. ${ }^{* * *}$ Significantly different from WT and EV groups at p<0.001. C, Western blot analysis of OGFr expression in three clones of MIA PaCa-2 cells (OGFr-1, -4 , and -7), and in WT and EV cells. Levels of OGFr protein were assessed in $80 \mu \mathrm{g}$ of nuclear lysate using anti-OGFr antibody (IO407) as described in the Materials and methods. The 62-kDa band of OGFr was detected in all cell lines. Membranes were stripped and reprobed with $\beta$-actin $(43-\mathrm{kDa})$ to visualize protein load. D, histogram of optical density ratios of OGFr/actin relative to WT. Values represent means \pm SE. ${ }^{* *}$ Significantly different from the EV group at $\mathrm{p}<0.01$ 
A

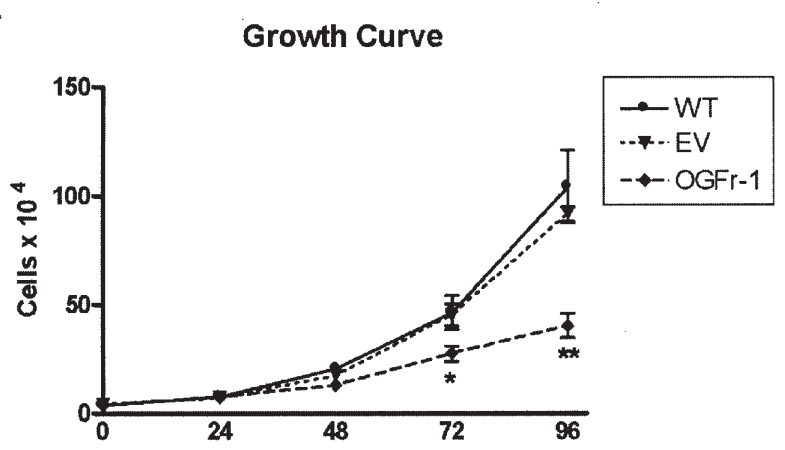

B

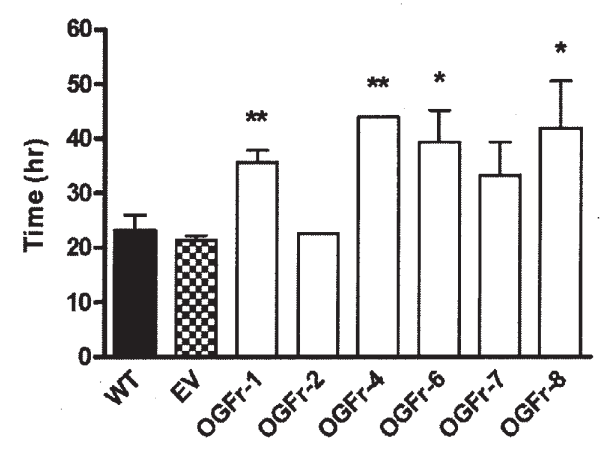

Figure 3. Decreases in growth of cells transfected with OGFr. A, representative growth curves of clonal cell lines OGFr-1 and EV, as well as parental MIA $\mathrm{PaCa}-2$ cells (WT). Values represent means $\pm \mathrm{SE}$ for at least 3 wells/time point/cell line. B, doubling times of six clonal cell lines overexpressing OGFr, as well as WT and EV MIA PaCa-2 cell lines. Values were calculated from 96-h growth curves and analyzed with regression analysis. Bars $=$ means $\pm \mathrm{SE}$ for at least 2 growth curves/cell line. Significantly different from WT and $\mathrm{EV}$ at ${ }^{*} \mathrm{p}<0.05$ and ${ }^{* *} \mathrm{p}<0.01 ; \mathrm{WT}$ and $\mathrm{EV}$ did not differ from one another.

shown). For all cell lines, OGFr was visible in the cytoplasm and the nucleus. Cells processed with secondary antibody only showed no staining (data not shown). Photodensitometric measurements (Fig. 2B) revealed that exposure times for clonal lines OGFr-1 and OGFr-7 were decreased by $43 \%$ and $38 \%$, respectively, compared to that of the WT group; exposure times of the WT and EV cells were similar. Thus, the decrease in photodensitometric values for OGFr in the OGFr-1 and OGFr-7 cell lines reflects the increased fluorescence from overexpression of OGFr protein.

Western blot analysis of OGFr in nuclear-enriched preparations indicated that the $62-\mathrm{kDa}$ band was present in all preparations (Fig. 2C). Densitometric analysis of films revealed that the $62-\mathrm{kDa}$ band of OGFr protein, standarized for loading with actin, was elevated 2.0-, 2.4- and 2.5-fold in clonal cell lines OGFr-1, -4 , and -7 , respectively, relative to WT cells (Fig. 2D); no differences were observed between the WT and EV cells.

Overexpression of OGFr downregulates cell proliferation. The functional repercussions of amplified OGFr in MIA $\mathrm{PaCa}-2$ were determined by evaluation of cell growth over a 96 -h period. In general, differences between cell lines overexpressing OGFr and the WT and EV cultures were detected at 48, 72, and/or $96 \mathrm{~h}$ after seeding (see Fig. 3A for

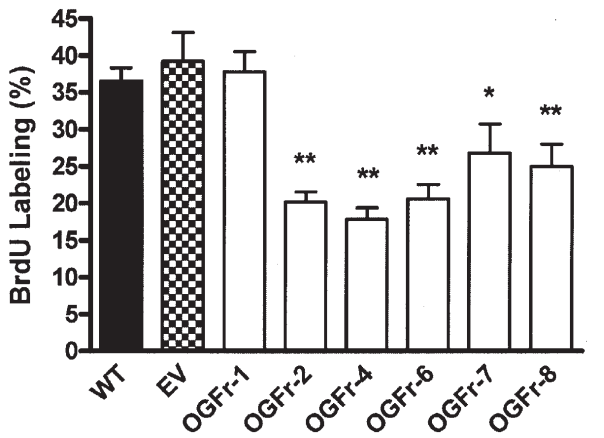

Figure 4. Suppression of DNA synthesis in cells overexpressing OGFr. Six MIA PaCa-2 cell lines amplifying OGFr, along with cells from the WT and EV groups, were evaluated for the percentage of BrdU labeling. Values represent means \pm SE for 10 fields per coverslip, and at least 2 coverslips/ cell line. Five of 6 transfected cell lines differed from WT and EV groups at ${ }^{*} \mathrm{p}<0.05$ and ${ }^{* *} \mathrm{p}<0.01$; values for the EV and WT groups were comparable.

a representative growth curve). Calculation of doubling times based on multiple growth curves/cell line revealed that in all but one of the clonal cell lines (OGFr-2), cells amplifying OGFr had a longer doubling time compared to the WT and $\mathrm{EV}$ groups that ranged from no changes in OGFr-2 to a $91 \%$ increase in the OGFr-4 group (Fig. 3B). No differences in doubling times were observed between the WT and EV groups $(\sim 22 \mathrm{~h})$.

DNA labeling indexes are decreased in cells with an abundance of OGFr. To assess one mechanism of the changes in growth observed in cell lines overexpressing OGFr, labeling indexes of clonal pancreatic cell lines subjected to BrdU were evaluated. In comparison to the labeling index of WT cells $(37.2 \pm 2.9 \%)$, 5 of 6 clonal cell lines overexpressing OGFr had 28-52\% fewer cells incorporating BrdU (Fig. 4). The WT and EV groups were similar concerning the number of labeled cells $(\sim 38 \%)$.

Addition of exogenous OGF to cell cultures overexpressing OGFr heightens the decreases in cell number. In earlier studies $(7,11,15)$, addition of exogenous OGF to pancreatic cancer cultures depressed cell growth, leading to the prediction that exogenous OGF introduced to cells overexpressing OGFr will have an exaggerated inhibitory response. In fact, the number of cells in cultures OGFr-1, $-4,-6$, and -7 was reduced by $13-38 \%$ compared to that in the WT cultures (Fig. 5A); no differences between the WT and EV groups were detected. The addition of exogenous OGF to these clonal cell lines depressed growth even further, reducing cell numbers by 14-31\% compared to their respective basal levels at $72 \mathrm{~h}$ (Fig. 5B). Summation of the percent basal growth inhibition calculated from cell number at $72 \mathrm{~h}$ and data on the percent inhibition of cell lines after exposure to OGF for $72 \mathrm{~h}$, showed a total growth inhibition of the clonal cell lines that was 1.6to 4.0-fold greater than that for the EV group, which had a $17 \%$ reduction (Fig. 5C).

The effect of exogenous OGF on the growth of cells transfected with OGFr is opioid receptor-mediated. To establish whether the growth inhibitory effects of OGF on cells overexpressing OGFr was receptor-mediated, cells were grown in the presence 
A

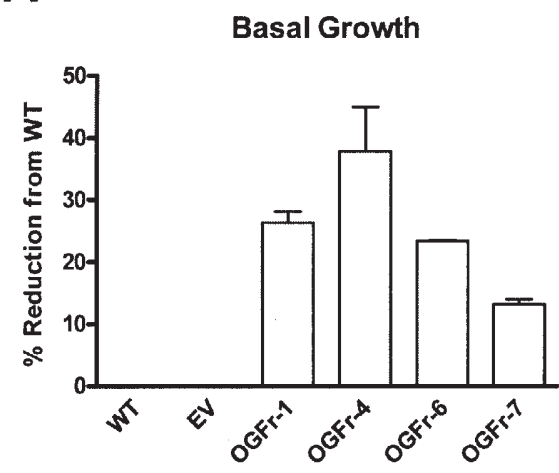

B

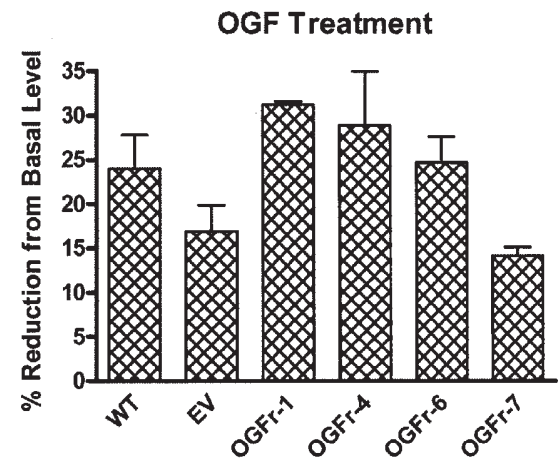

C

Total Growth Inhibition Index

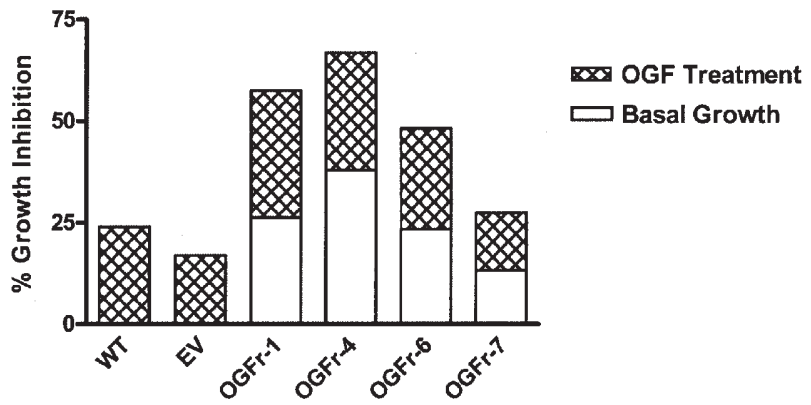

Figure 5. Endogenous and exogenous OGF had an additive effect on depressing the growth of cells transfected with OGFr. Basal growth (A) and the effect of adding exogenous OGF $\left(5 \times 10^{-6} \mathrm{M}\right)(\mathrm{B})$ to clonal cell lines for $72 \mathrm{~h}$. All values are means \pm SE. A, growth is expressed as the percent reduction from WT. The basal growth of clonal cell lines was reduced by 13-38\% compared to the WT group; no difference between the WT and EV groups was recorded. B, exposure to OGF reduced cell growth respective to basal levels by $14-31 \%$ in all groups. C, total growth inhibition as determined by the sum of the percentage of decrease in cell number in clonal cell lines relative to WT cells (= basal level) after $72 \mathrm{~h}$ in culture, and the decrease in cell number following exposure of each cell line to $5 \times 10^{-6} \mathrm{M}$ OGF for $72 \mathrm{~h}$ (OGF treatment).

of the short-acting opioid antagonist, naloxone, to temporarily block opioid receptors (Fig. 6). Cell lines with amplified OGFr (OGFr-7) and treated with $5 \times 10^{-6} \mathrm{M}$ OGF had a $14 \%$ decrease in cell number at $72 \mathrm{~h}$ compared to cells receiving sterile water, whereas the EV cells receiving OGF decreased $9 \%$ in cell number compared to their respective basal levels. Addition of $10^{-5} \mathrm{M}$ naloxone to cultures exposed to $5 \times 10^{-6} \mathrm{M}$ OGF, revealed that the EV and OGFr-7 cultures had cell numbers comparable to their respective basal levels. Moreover, cultures of EV and OGFr-7 cells exposed to $10^{-5} \mathrm{M}$ naloxone alone demonstrated no growth inhibition.

Naltrexone increases cell number in cells overexpressing $O G F r$. To understand the effects of opioid receptor blockade with a potent and long-acting opioid receptor antagonist on cells with an abundance of OGFr, NTX was added to cultures of clonal cell lines (Fig. 7). Clonal lines subjected to two concentrations of NTX exhibited an increased cell number compared to basal levels in OGFr-1, OGFr-4, and EV cultures. However, the magnitude of change was greater in clonal cell lines OGFr-1 and OGFr-4 than in the EV cells, and this was especially noticeable with $5 \times 10^{-5}$ M NTX. Thus, EV, OGFr-1, and OGFr-4 cell lines increased 45\%, 44\%, and 5.2-fold, respectively, when subjected to NTX at a concentration of
$10^{-5} \mathrm{M}$, and increased 32\%, 2.3-fold, and 9.4-fold, respectively, when exposed to $5 \times 10^{-5} \mathrm{M}$ NTX.

OGF is the specific opioid peptide that depresses growth in cells overexpressing OGFr. Although opioid peptides other than OGF have not been found to influence the growth of human pancreatic cancer cells in culture (7), the effects of these other opioid peptides on the growth of cells overexpressing OGFr required elucidation. OGFr-1 and OGFr-7 cells were treated daily with $10^{-6} \mathrm{M}$ concentrations of a variety of natural and synthetic opioid ligands; in some cases, these ligands were specific for $\mu, \delta$, or $\kappa$ opioid receptors. Morphine, DAMGO, DPDPE (d-Pen,d-Pen-enkephalin), dynorphin 1-13, endomorphin-1, endomorphin-2, U69,593, and ß-endorphin were not found to alter the growth of either clonal cell line (data not shown).

Increased proliferation of transfected cells with OGFr exposed to an $O G F$ antibody. In order to examine the repercussion of depleting endogenous OGF in cultures of cells overexpressing OGFr, WT, OGFr-1, and OGFr-7 cell lines were seeded in 96-well plates and allowed $24 \mathrm{~h}$ before addition of the OGF antibody CO172; media and antibody were replaced daily. At 72 h, OGFr-1 and OGFr-7 cells exposed to OGF antibody 

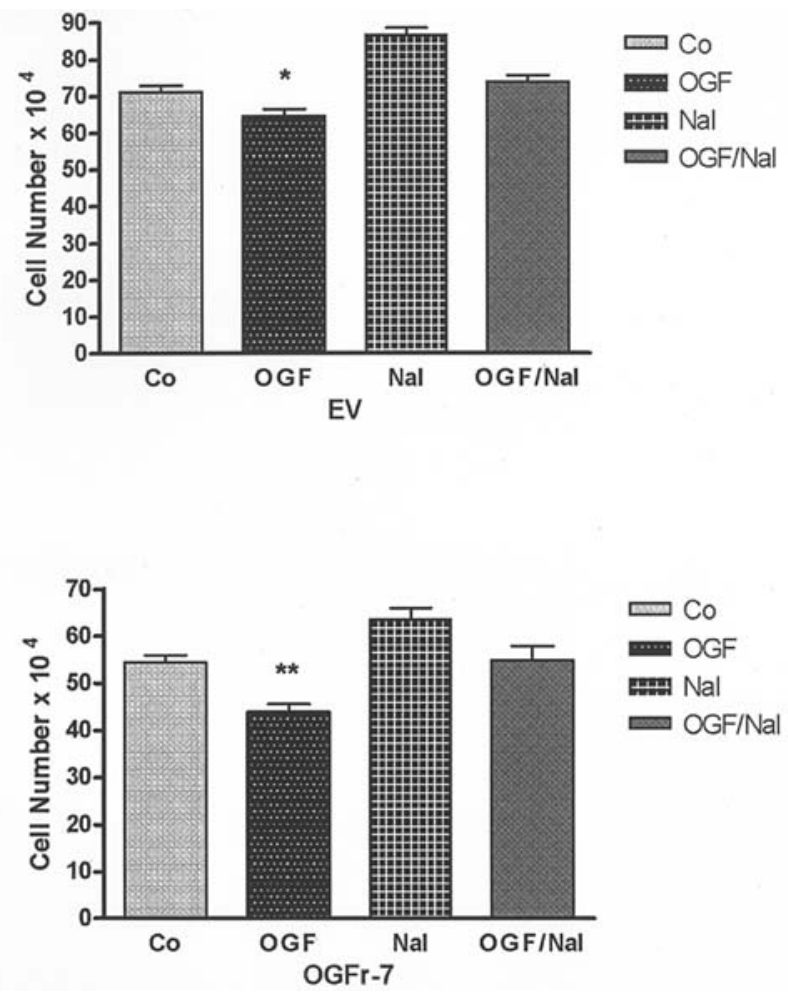

Figure 6. The decrease in cell proliferation by exogenous OGF was receptormediated in cells transfected with OGFr. The number of cells in EV and clonal cell line OGFr-7 following treatment for $72 \mathrm{~h}$ with OGF $\left(5 \times 10^{-6} \mathrm{M}\right)$, OGF $\left(5 \times 10^{-6} \mathrm{M}\right)$ and naloxone (Nal) $\left(10^{-5} \mathrm{M}\right)$, Nal, and sterile water $(\mathrm{Co})$. Media and compounds were changed daily. Data represent means \pm SE for 2 aliquots/well, 3 wells/group. Significantly different from controls at ${ }^{*} \mathrm{p}<0.05$ and ${ }^{* *} \mathrm{p}<0.01$.

had $50 \%$ and $37 \%$, respectively, more cells than transfected cell lines receiving sterile vehicle. WT cells subjected to OGF antibody had a $46 \%$ increase in cell number.

\section{Discussion}

This study provides major insights into the molecular mechanisms of the OGF-OGFr axis and is the first to report the successful stable transfection of the OGF receptor, with resulting translation of OGFr protein, in a cancer cell line. Receptor binding assays of clonal cell lines using radiolabeled OGF ligand showed 2.3- to 5.6-fold more receptors in these cells than in WT or EV cell lines. As expected, the molecular and cellular nature of the amplified OGFr protein was not changed with respect to binding affinity, permitting an understanding of the biological effects solely from increasing the number of OGF receptors. Qualitative and quantitative immunohistochemical staining of OGFr in clonal cell lines revealed a substantial increase of this receptor protein in these cells compared to WT and EV cell lines, however the location and distribution of OGFr in clonal cells did not differ from that in WT or EV cells. Protein expression of OGFr in clonal lines was increased from WT and EV groups as measured by Western blotting. It should be noted that WT and EV cell lines were similar in all experiments (e.g. protein levels, receptor binding), arguing that the vector itself was not a confounding influence. Moreover, the selection and characterization of six clonal lines insured that the outcome
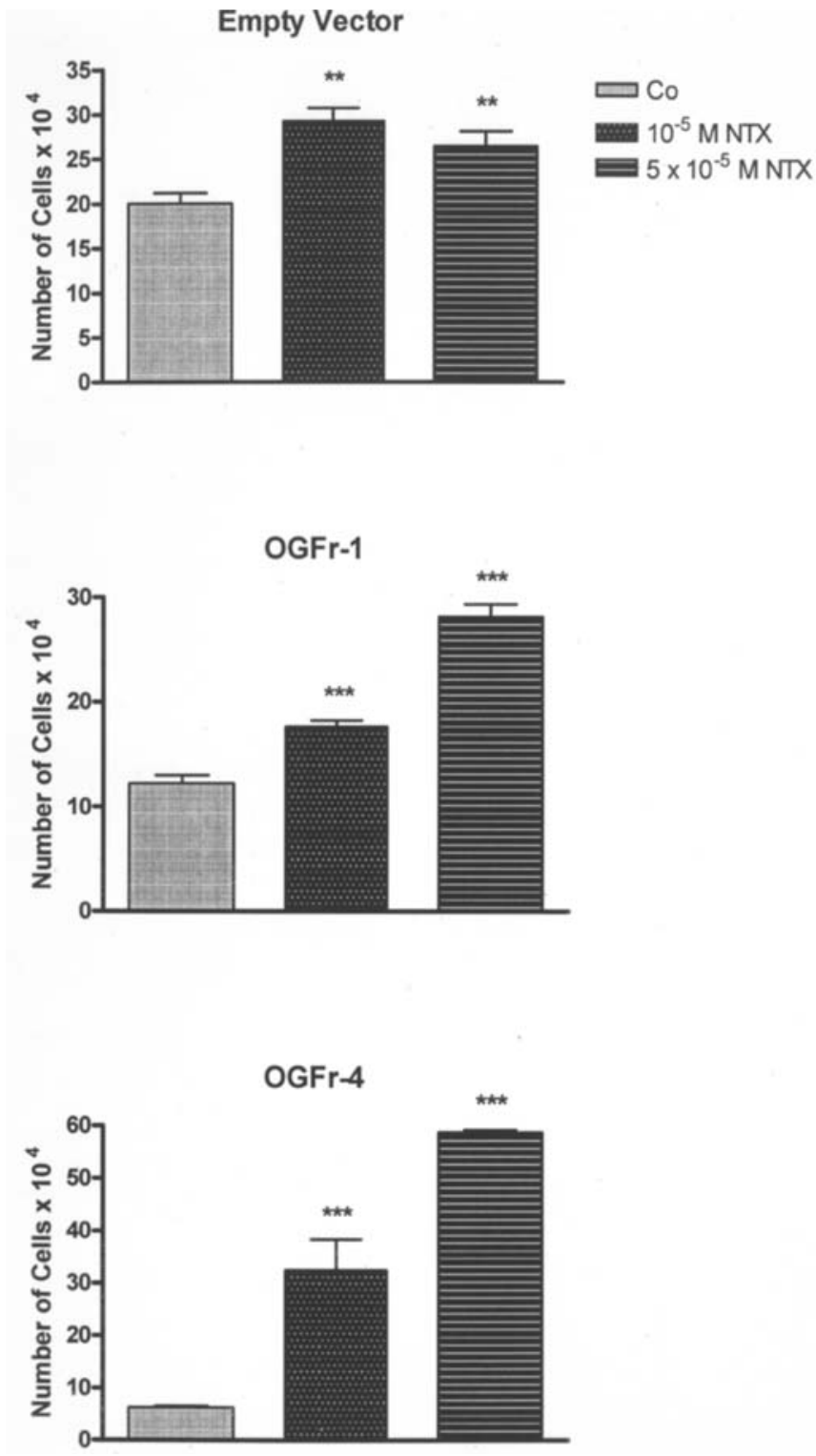

Figure 7. Continuous opioid receptor blockade by NTX of cells transfected with OGFr increased cell number. The number of cells in EV and clonal cell lines OGFr-1 and OGFr-4 following treatment for $48 \mathrm{~h}$ with $10^{-5} \mathrm{M}$ NTX, $5 \times 10^{-5} \mathrm{NTX}$, or/and equivalent volume of sterile water (Co). Media and compounds were changed daily. Data represent means \pm SE for 2 aliquots/ well, 3 wells/group. Significantly different from controls at ${ }^{* *} \mathrm{p}<0.01$ and **** $\mathrm{p}<0.001$.

of the transfection was not an isolated observation in one clonal cell line.

This report is the original observation revealing that targeted overexpression of the OGF receptor has marked repercussions on growth and DNA synthesis of human pancreatic cancer cells. All clonal lines had decreased DNA synthesis by up to $50 \%$ compared to the parental line or EV. Moreover, doubling times of all but one MIA PaCa- 2 cell line transfected with OGFr cDNA were increased by more than $50 \%$ compared to WT and EV cells. Four of the clonal cell lines exhibited 13-38\% decreases in cell number relative to either the parental cell line or that of the EV, indicating that the overexpression of OGF receptors altered the basal level of cellular duplication. These results are consistent with previous reports that the OGF-OGFr axis is targeted to cyclin- 
dependent inhibitory kinases (Cheng F, et al, AACR 97th Ann Meet: abs. 2077, 2006). This would suggest that the equilibrium in cell replication is disturbed by the addition of OGF receptors, with the net result being an exaggeration in growth inhibition and diminishment in cell number. The sensitivity of cellular events to the addition of OGF receptors was also observed when exogenous OGF was added to the cultures and the clonal cell lines had even further reductions (by 14-31\% compared to respective basal levels) in growth. Thus, despite the increase in OGF there are a sufficient number of OGF receptors to respond to even higher levels of peptide. Moreover, the magnitude of expression of OGFr is rate limiting for OGFr signaling, and is an absolute requirement for activation of the OGF pathway. In addition, the effects of exogenous OGF on cells with amplified receptors was receptormediated, as demonstrated by the neutralization of OGF action with naloxone. Finally, the total growth inhibition of clonal cell lines with respect to the summation of basal levels and addition of exogenous OGF, decreased cell number by 1.6- to 3-fold compared to that of the WT and EV cells exposed to OGF. These data indicate that introduction of OGFr cDNA into these neoplastic cells has dramatic effects on growth by activating the OGF-OGFr inhibitory axis. Conversely, it might be conjectured that underexpression of OGFr could confer a growth advantage to the progression of pancreatic cancer. Future studies that attenuate OGFr in pancreatic cancer are required to examine this hypothesis.

Examination of the data revealed that receptor number alone could not be used as a predictor of growth. For example, one clonal cell line that had 4.4 -fold more receptors than parental cells displayed a $13 \%$ decrease in basal growth, whereas another clonal cell line that had a 3.4-fold increase in binding capacity exhibited a $38 \%$ decrease in cell number. Thus, although the integrity of the OGF receptors appeared to be intact based on binding experiments and protein levels, other factors (e.g. nucleocytoplasmic transport) appeared to be at work in determining function. Such observations of differences in transfection studies between translation and function have been reported previously $(23,24)$. However placing this clonal variation aside, it should be emphasized that all of the cell lines with increased OGF receptors had marked alterations in cell replication.

In previous reports, OGF has been identified as the opioid peptide that binds to OGFr and activates a response signal in pancreatic cancer (7). This peptide has been found to be produced and secreted by a variety of cells so that the elements regulating cell proliferation are dependent on the cell itself $(6,7)$. In the present study, a test of this ligand-dependent axis was made in clonal cell lines overexpressing OGFr by subjecting these cells in culture to an antibody to OGF. As in the WT and EV cells exposed to the antibody to OGF, clonal cells with enhanced expression of OGFr increased in number compared to the levels of those not treated with the antibody. Thus, cells overexpressing OGFr reacted in the predicted manner to depletion of OGF from the culture media. These data are consistent with the postulate that the OGF-OGFr axis is in an autocrine loop and integral to the regulation of pancreatic cancer, with disturbances of peptide or receptor markedly altering homeostatic equilibrium and bringing about changes in growth.
The finding that OGFr is activated by OGF raises the question of whether the changes seen in growth by clonal lines were due, wholly or in part, to increases in OGF levels because of a compensatory mechanism related to the abundance of the receptor. A number of observations argue that this is not the case. First, if OGF increased in proportion to the abundance of OGF receptors, then one would predict that clonal lines with the greatest number of receptors would have the highest levels of opioids and the largest decreases in growth. However, as mentioned earlier, no correlation was found between factors such as the number of OGF receptors and growth effects. Second, previous experiments with opioid receptor blockade using opioid antagonists have shown an upregulation of opioid peptides, so that an abundance of opioid agonists would be expected to result in a downregulation, rather than an upregulation, of opioid levels. Therefore, although there is a need to examine OGF levels in cultures of clonal cell lines with amplification of OGFr, it would not appear that changes in OGF values as a result of OGFr overexpression are responsible for the observed growth alterations.

The present observations on the effects of additional OGF receptors in pancreatic cancer cells with respect to growth complement those in previous studies regarding changing OGF-OGFr interactions. Antisense technology which attenuates OGFr levels has revealed marked increases in the number of human neuroblastoma and rat intestinal epithelial cells compared to control levels $(6,14)$, whereas blockade of OGFOGFr interactions with opioid antagonists such as naltrexone also elevates cell number, including that of pancreatic cells such as MIA PaCa-2 $(7,15)$. These findings are consistent with the present results showing that overexpression of OGFr decreases the number of pancreatic cancer cells, and that exposure to NTX increases cell replication. Our data are also consistant with reports that transient transfection of OGFr cDNA into rat corneal epithelial cells in vivo using a gene gun depresses DNA synthesis (25) and wound healing (26). We now show that stable transfections of OGFr cDNA can markedly suppress cell growth in a cancer cell under in vitro conditions. Whether these pancreatic cancer cells with an overexpression of OGFr also have delays in growth in vivo remains to be determined.

Clinically, the OGF-OGFr axis has been detected using receptor binding, immunohistochemistry, and Western blotting in biopsy and surgical specimens of human pancreatic cancer $(8,14)$. Studies on the transplantation of human pancreatic cancer cells into nude mice have revealed that the OGF-OGFr axis is functional in vivo $(11,12)$. Given that pancreatic cancer is the 9th leading cause of mortality in the world (2), and that the survival rate for this neoplasia has not improved substantially in decades (1), strategies for treatment of this lethal cancer are needed. In the present study, we found that introduction of additional OGFr into pancreatic cancer has a dramatic effect on cell number. Therefore, gene therapy to reinstate OGFr with functional effects could provide a useful treatment for inhibiting tumor progression.

\section{Acknowledgements}

Supported by a grant from Philip Morris USA Inc. and Philip Morris International. 


\section{References}

1. Jemal A, Siegel R, Ward E, Murray T, Xu J, Smigal C and Thun MJ: Cancer statistics, 2006. CA Cancer J Clin 56: 106-130, 2006.

2. Parkin DM, Pisani P and Ferlay J: Global cancer statistics. CA Cancer J Clin 49: 33-64, 1999.

3. Mancuso A, Calabro F and Sternberg CN: Current therapies and advances in the treatment of pancreatic cancer. Critical Rev Oncol Hematol 58: 231-241, 2006.

4. Akerele CE, Rybalova I, Kaufman HL and Mani S: Current approaches to novel therapeutics in pancreatic cancer. Invest New Drugs 21: 113-129, 2003.

5. Li D, Xie K, Wolff R and Abbruzzese JL: Pancreatic cancer. Lancet 363: 1049-1057, 2004.

6. Zagon IS, Verderame MF and McLaughlin PJ: The biology of the opioid growth factor receptor (OGFr). Brain Res Rev 38: 351-376, 2002.

7. Zagon IS, Smith JP and McLaughlin PJ: Human pancreatic cancer cell proliferation in tissue culture is tonically inhibited by opioid growth factor. Int J Oncol 14: 577-584, 1999.

8. Zagon IS, Smith JP, Conter R and McLaughlin PJ: Identification and characterization of opioid growth factor receptor in human pancreatic adenocarcinoma. Int J Mol Med 5: 77-84, 2000.

9. Smith JP, Conter R, Demers LM, McLaughlin PJ and Zagon IS: Elevated levels of opioid growth factor in the plasma of patients with pancreatic cancer. Pancreas 21: 158-164, 2000.

10. Smith JP, Ahmad M, Conter R, Bingaman S, Harvey H, Mauger D, Demers L, McLaughlin PJ, Stanley W and Zagon IS: Treatment of advanced pancreatic cancer with opioid growth factor. Anti-Cancer Drugs 15: 203-209, 2004.

11.Zagon IS, Jaglowski JR, Verderame MF, Smith JP, Leure-duPree AE and McLaughlin PJ: Combination chemotherapy with gemcitabine and biotherapy with opioid growth factor (OGF) enhances the growth inhibition of pancreatic adenocarcinoma. Cancer Chemother Pharmacol 56: 510-520, 2005.

12. Zagon IS, Hytrek SD, Smith JP and McLaughlin PJ: Opioid growth factor (OGF) inhibits human pancreatic cancer transplanted into nude mice. Cancer Lett 112: 167-175, 1997.

13. Zagon IS and McLaughlin PJ: Progression of human pancreatic and colon cancers is not associated with alterations in transcription and translation of opioid growth factor (OGFr). Int J Oncol 29: 489-494, 2006.
14. Zagon IS, Verderame MF, Allen SS and McLaughlin PJ: Cloning, sequencing, chromosomal location, and function of a cDNA encoding the opioid growth factor receptor (OGFr) in humans. Brain Res 856: 75-83, 2000.

15. Zagon IS, Roesener CD, Verderame MF, Levin RJ and McLaughlin PJ: Opioid growth factor regulates the cell cycle of human neoplasias. Int J Oncol 17: 1053-1061, 2000.

16. Zagon IS and McLaughlin PJ: Opioids and the apoptotic pathway in human cancer cells. Neuropeptides 37: 79-88, 2003.

17. Zagon IS and McLaughlin PJ: Opioid growth factor (OGF) inhibits anchorage-independent growth in human cancer cells. Int J Oncol 24: 1443-1448, 2004

18. Zagon IS and McLaughlin PJ: Opioid growth factor, opioids, and differentiation of human cancer cells. Neuropeptides 39: 495-505, 2005.

19. Zagon IS, Ruth TB, Leure-duPree AE, Sassani JW and McLaughlin PJ: Immunoelectron microscopic localization of the opioid growth factor receptor (OGFr) and OGF in the cornea. Brain Res 967: 37-47, 2003.

20. Zagon IS, Ruth TB and McLaughlin PJ: Nucleocytoplasmic distribution of opioid growth factor (OGF) and its receptor (OGFr) in tongue epithelium. Anat Rec 282A: 24-37, 2005.

21. Yunis AA, Arimura GK and Russin DJ: Human pancreatic carcinoma (MIA PaCa-2) in continuous culture: Sensitivity to asparaginase. Int J Cancer 19: 128-135, 1977.

22. Zagon IS, Verderame MF, Allen SS and McLaughlin PJ: Cloning, sequencing, expression, and function of a cDNA encoding a receptor for the opioid growth factor, [Met $\left.{ }^{5}\right]$ enkephalin. Brain Res 849: 147-154, 1999.

23. Ling M-T, Lau TCM, Zhou C, Chua CW, Kwok WK, Wang Q, Wang X and Wong Y-C: Overexpression of Id-1 in prostate cancer cells promotes angiogenesis through the activation of vascular endothelial growth factor (VEGF). Carcinogenesis 26: 1668-1676, 2005

24. Surmacz E and Burgaud J-L: Overexpression of insulin receptor substrate 1 (IRS-1) in the human breast cancer cell line MCF-7 induces loss of estrogen requirements for growth and transformation. Clin Cancer Res 1: 1429-1436, 1995.

25. Zagon IS, Sassani JW, Verderame MF and McLaughlin PJ: Particle-mediated gene transfer of OGFr cDNA regulates cell proliferation of the corneal epithelium. Cornea 24: 614-619, 2005.

26. Zagon IS, Sassani JW, Malefyt KJ and McLaughlin PJ: Particlemediated gene transfer of OGFr cDNA regulates corneal repair. Arch Ophthalmol 124: 1620-1624, 2006. 